\title{
Labor Supply Elasticity in the Unconditional Basic Income System: Data Sources and Methodological Issues
}

\author{
Jitka Specianova \\ University of Economics, Prague, Czech Republic
}

Doi: 10.19044/esj.2018.v14n4p13 URL:http://dx.doi.org/10.19044/esj.2018.v14n4p13

\begin{abstract}
This study deals with five sources of data that may help to answer the question of how labor supply would respond to the introduction of unconditional basic income. Research of lottery winners' labor supply and the results of field experiments, in which the behavior of households who have received a regular unconditional income for a limited time period was observed and is then investigated and discussed. Results of the laboratory experiment, the estimates of microsimulation models, and the results of the opinion polls are also examined. The surveyed data sources show mainly a slight decline in labor supply. However, none of these data were collected in situations that would fully correspond with the expected conditions of decision-making that would occur with the basic income. Any results derived from them therefore need to be considered with caution.
\end{abstract}

Keywords: Unconditional basic income, labor supply elasticity, field experiments, methodological limitations

\section{Introduction}

At present, a global debate on the so-called Fourth Industrial Revolution (or Industry 4.0) is under way in the developed world. In this context, there is also an extensive reform of the current social systems considered, namely a transition from means tested social benefits to an unconditional basic income (UBI). Defense of the UBI is based on the argument of technological changes in the labor market, i.e. the expectation that automation will gradually replace human labor (Ford, 2016). Were technological unemployment to occur on a mass scale, UBI should ensure decent living conditions for all members of society, because some of them lose their ability to secure themselves by participating in the labor market due to technological unemployment. 
UBI is defined as a universal, individually and unconditionally paid benefit that must be sufficient to allow a dignified human existence (BIEN, 2017). It represents a regular cash payment to an individual citizen. The payment is independent of the size of a person's income, his wealth or the size of his family, nor is it subject to unemployment or any other conditions. Every citizen should be entitled to the same amount of basic income. For children, UBI is also considered, but at a lower rate than for adults. A "sufficiently large" UBI is often considered to be equivalent to the official poverty threshold, i.e. 50-60\% of the median income (Raventos, 2007). UBI would replace the current social system and substitute the other social benefits.

In the second half of the 20th century, the growing interest in the UBI in the US, Canada and Europe stemmed from the need to simplify the current social welfare system, which had high administrative costs, lacked transparency, and locked many of the poor in an unemployment trap due to high effective marginal tax rate upon entering the labor market. UBI in the shape of a negative income tax was considered by prominent economists in the 1960s (Friedman, 1962; Tobin, 1966) as a possibly more efficient tool of social policy in the fight against poverty. Criticism of the UBI, on the other hand, has emphasized concerns about the decline in labor supply caused by introduction of such a scheme (e.g. Elster, 1986; Galston, 2000; Anderson, 2000; Schneider, 2016). How much less will the citizens work if they receive UBI? How would their labor supply drop due to the increase in income tax that is usually considered necessary to fund the UBI?

Revenue from income taxation is the most frequently suggested way of funding the UBI. In addition, its proponents propose higher environmental taxation, consumption tax, property tax, inheritance tax, or introduction of new types of taxes, such as financial transaction tax. (Healy et al., 2012; Van Parijs \& Vanderborght, 2012; Groot, 2004; Van Parijs, 2000)

The key challenge for both critics and advocates of basic income is to answer these questions as convincingly as possible. A reduced labor supply would cause problems with funding the UBI and would therefore require the search for new sources of tax revenue, such as the work of robots. Given the fact that a full-scale UBI has never been tried in practice, it is difficult to predict how people's labor supply would change, and how they would change their behavior in other areas (education, investment, etc.). The aim of this text is therefore to identify and analyze data sources that could help us to reveal the labor supply response to UBI. Methodological problems of five different data sources will be discussed.

Since the UBI, which meets all the characteristics, has not been implemented yet in any country in the world, it will be necessary to rely on "second-best" data. Similar to UBI's payees, the lottery winners face to analogical conditions when they receive a regular monthly fee. Another 
relevant approximation of the individual's situation when receiving an UBI were pilot projects testing negative income tax in the United States and Canada in the 1960s and 1970s. Another form of setting up similar conditions was a laboratory experiment measuring labor productivity at unconditional reward with respect to the group that was rewarded according to its performance. Another source of data is the outputs of models that simulate the introduction of a system of UBI and increased taxation, and which also estimate the impact on labor supply. The latest way to determine future change in the labor supply are the opinion surveys, in which the respondents' attitudes are directly surveyed.

The first part of the paper focuses on studies of labor supply elasticity in the case of a newly acquired regular non-labor income. The second part deals with pilot projects in which the UBI was tested on a selected sample of the population. The third part discusses results of an UBI laboratory experiment. The fourth part deals with estimations of microsimulation models, and the fifth part with opinion surveys investigating potential changes in the respondents' working regime. The last part draws conclusions regarding the expected changes in the labor supply in response to UBI.

\section{Labor supply responses of lottery winners}

The first source of potentially relevant information on labor supply elasticity are the studies that concentrate on people who have started receiving a non-labor income. Winning a lottery is very similar to UBI as far as the winnings are received in form of a monthly rent. There are several studies that have examined the change in the work behavior of winners of high financial volumes. The share of the lottery winners who have completely withdrawn from the labor market ranges from about $8 \%$ to almost 50\% (Hedenus, 2012). For instance, in 2004, 83 Belgian lottery winners participated in a labor supply research. They received a monthly rent of $€ 1,000$. Out of the 13 winners living in the single-person household, 12 worked after the winning, out of 43 winners living in a household with a partner three ceased to work. Only four participants reported a reduction in the number of hours they worked, and no one started doing business. Participants also reported that winning has greatly helped to reduce financial uncertainty in life, allowing them to make more thoughtful decisions about important life choices. (Marx \& Peeters, 2004)

The behavior of 237 lottery winners in Massachusetts from 1984 to 1988 was also investigated. They received a very high prize paid in annual installments for 20 years. The lower labor earnings of the winners of extreme amounts was measured out compared to those who won a one-off lower amount. The income elasticity of the labor supply was high: -0.11 for the winners of high prizes and -0.17 for winners aged 55-65 (Imbens, Rubin \& Sacerdote, 2001). A slight decline in labor supply after the win was found in 
other studies too. Out of the 185 lottery winners in Ohio and Iowa between 1985 and 1999, 6\% stopped working and 14\% started to work part-time. Job satisfaction, an important job position in the winner's personal life, and the size of the prize have all emerged as the strongest determinants in deciding whether to continue working or to leave the labor market. The winners with higher education have left the labor market less frequently, older people more often, on the contrary. (Arvey, Harpaz \& Liao, 2004)

A decrease in labor supply was also recorded for Swedish lottery winners. Out of 309, 11\% left the labor market, and $14 \%$ reduced the number of hours worked. Women were more likely than men to leave the labor market or reduce their labor supply. The winners whose job was physically demanding ceased to work more often. However, no significant difference in changes in the labor supply between "blue" and "white" collar workers has been found in this study (Hedenus, 2012). The influence of job satisfaction was confirmed by research on less than 600 US lottery winners. The winners working in low qualified positions have left the labor market far more often than those who have worked in positions were both psychologically and financially satisfying. $23 \%$ of dollar millionaires left the labor market, $8 \%$ of all surveyed winners reduced the number of hours worked. Higher education, longer tenure, and a higher wage were positively correlated with the decision to continue to work. (Kaplan, 1987)

These studies confirm the theoretical prediction that increase in nonlabor income leads to a decrease in the quantity of labor supplied. The decrease is, however, slight. Its magnitude depends on several factors: the height of the non-labor income, the satisfaction derived from the current job, the perception of the job as a part of daily life, age, education, gender, and status in some studies.

\section{Methodological limitations of research on lottery winners}

The research on lottery winners is only partially relevant in the context of UBI because it has several important methodological limitations. There is the possible problem of selection bias as the response rate within the targeted population was only $24-45 \%$ in the studies. The response of the invited winners to the researchers' call was around $24-45 \%$. Therefore, the results may be distorted by a selection bias, for example, if more winners who did not stop working joined the study. The sample may therefore not be representative. The research also relies on the self-reported information about labor supply, which may not be fully reliable. Also, the monthly rent of lottery winners was significantly higher than the proposed UBI.

Another setback is that the institutional ceteris paribus would not hold if UBI were introduced. The negative impact on the labor supply of non-labor income would most probably be further strengthened by the increase in 
income tax rates. ${ }^{1}$ It is also important to keep in mind the institutional set-up of states. If universal income for all residents were introduced, unforseen institutional changes would be expected and this could lead to an impact that the research on lottery winners in which other residents did not receive regular benefits, could not capture. The study on the winners also cannot show the effect of the higher income tax that would fund basic income.

\section{Field experiments with unconditional basic income}

Experimental research represents another valuable source of data for the estimates of the labor supply elasticity. The experiments testing UBI began in the late 1960s in the US and a few years later in Canada. In all cases, this was a controlled experiment aimed at evaluating the results on the experimental group compared to the control group. The experimental group received the UBI in the form of a negative income tax, while the control group had access to the existing social welfare system. The researchers focused mainly on the effect of UBI on the number of hours worked by the individual members of the household, on health, educational outcomes, and school attendance. Also changes in household spending and the structure of families were examined in the later projects. Some experiments were accompanied by financial problems arising from a change in the political representation which had to approve the financial resources. The field experiments had various designs that differed in the number of experimental households, their characteristics, the negative income tax rate, the marginal tax rate, the duration of the experiment, and also in variables that were subject to examination. The marginal tax rate reduced the amount of negative income tax regarding each dollar earned by households.

The first of the US field experiments was conducted in New Jersey in the cities of Trenton, Paterson, Passaic and Jersey City, and in Scranton, Pennsylvania, between 1968-1972. In New Jersey, more than half of the experimental group were African-American or Hispanic households, in Scranton the participants were mainly Caucasian. In New Jersey, only households with at least one working man aged 18-58 and at least one other member was selected, whose income did not exceed $150 \%$ of the relative poverty line. 1,357 families were divided into eight different negative income tax plans ranging from 50 to $125 \%$ of the relative poverty line. The amount received via the negative income tax was subject to reduction by 30-70\% if the family also reported labor income. The marginal tax rate was therefore relatively substantial. (Carfinkel, 1972)

\footnotetext{
${ }^{1}$ Based on microsimulations a $50 \%$ individual income tax rate is often suggested to make UBI fiscally neutral (e.g. Colombino \& Narazani, 2013; Arcarons, Raventos \& Torrens, 2014).
} 
After the first year of the field experiment, there had been a $11.8 \%$ drop in hours worked in the experimental group as compared to the control group. Its earnings also dropped by $3.2 \%$, but the difference was not statistically significant. Compared to the control group, the hourly wage in the experimental group was about $10 \%$ higher. A possible explanation is that the negative income tax allowed the recipients to be more selective when choosing a job. They searched for work longer and were financially secure when they left their jobs. Married men reported a $6.2 \%$ decrease in hours worked, married women a $25.2 \%$ decrease, and other working household members $41.1 \%$. However, the results for the two latter groups were statistically insignificant. (Carfinkel, 1972) The four years of experimental data yielded an elasticity estimate of -0.02 with respect to non-labor income and 0.14 with respect to wage. (Hausman \& Wise, 1976)

The largest pilot project with negative income tax was conducted in Seattle and Denver from 1971-1982. 4,801 households participated in the experiment (2,043 from Seattle and 2,758 from Denver). The size of the control group was 1,041 households. (Munnell, 1987) Again, low-income families with one or two adults and at least one dependent member were selected. The sample included Caucasian, African-American and Hispanic families. The heads of the family had to be 18-58 years old. The families received a negative income tax for three, five or twenty years in Denver. There were 11 different plans, which varied in the amount of the negative income tax. The lowest negative tax was $90 \%$ of the relative poverty line, followed by $125 \%$, and the highest $140 \%$. The plans also varied in marginal tax rates: there was either a constant rate of $50 \%$ or $70 \%$, or $70 \%$ and $80 \%$, which decreased by 2.5 pp. with each additional \$ 1,000 earned. (Neubeck \& Roach, 1981)

The results of the first two and a half years of the field experiment have shown that plans with higher negative taxes and higher marginal taxes have a greater impact on labor supply. The negative income tax rate of $100 \%$ of the poverty line and $70 \%$ marginal tax rate reduced the number of hours worked by $10.9 \%$ for married men, $32 \%$ for married women and $14.9 \%$ for single mothers. The married men from families with a negative income tax of $75 \%$ of the poverty line with $50 \%$ marginal tax rate reduced the number of hours worked by $5.9 \%$, married women by $22.8 \%$ and single mothers by $6.7 \%$. (Neubeck \& Roach, 1981)

The data from the entire duration of the experiment show a decline of hours worked for married men by a maximum of $7.3 \%$ in a three-year plan and $13.6 \%$ over a five-year period. In absolute figures, there was a decrease by 133 and 234 hours worked per year, respectively. The married women reduced their labor supply by a maximum of $15.2 \%$ in the three-year plan and $27.1 \%$ for the five-year term. In absolute numbers, the decrease in hours worked per 
year was slightly over 100 and 200 hours, respectively. The greatest drop in hours worked was recorded for single mothers. The maximum decline in the three-year plan was $21.6 \%$, and $31.8 \%$ in a five-year, which is 220 and 405 hours a year for each respectively. (Office of the Assistant Secretary for Planning and Evaluation, 1983)

Two other negative tax pilot projects took place in the US in the early $1970 \mathrm{~s}$ in rural areas in Iowa and Indiana. Both lasted three years. The aggregate results of all four US negative income tax pilot projects show an average drop in hours worked by $7 \%$ for men and $17 \%$ for women (Munnell, 1987). The experimental households worked $13 \%$ less on average (Levine \& al., 2005). On the other hand, the negative income tax encouraged school attendance, which thus replaced the decline in the young people's work participation. The research also examined whether households changed their consumption behavior or investment decision-making. No change was observed compared to the control group. There was also no improvement in the health status of the recipients. (Munnell, 1987)

The impacts of the negative income tax were also examined in a Canadian field experiment. Between 1974 and 1979 a pilot project in the province of Manitoba took place in the cities of Dauphin and Winnipeg. Altogether, 1,300 poor families were involved in the experiment. In Winnipeg, seven different schemes were tested, and another in Dauphin. The experiment, however, suffered from problems with funding along the way. In the 1970s, Canada had to deal with the effects of oil shocks and a persistent stagflation and the experiment was prematurely terminated for financial reasons. The financial resources were insufficient to analyze instantly acquired data, especially those that showed the impact on labor supply.

Only in the 1990s, the first results showing the impact of the negative tax on the number of hours worked were published. The recorded decline in labor supply by married men was $1 \%$, for married women $3 \%$, and $7 \%$ for single mothers (Hum \& Simpson, 1993). However, the results were statistically insignificant. Forget (2011) analyzed the data on health status and education. The results show a higher probability of one additional year of child education in the tested families compared to the control group. The number of hospitalizations, mostly due to injuries or mental illness, declined by $8.5 \%$. Also visits to a doctor dropped. At the same time, there was no systematic evidence for changes in fertility or family structure.

Currently, an UBI experiment is taking place in Finland. The Finnish Social Security Administration (KELA) launched it on January 1, 2017. The aim of the experiment is to find out whether it would be possible to reform the current Finnish social welfare system into using the UBI to decrease unemployment and administration costs. According to KELA (2016), the current trends in the labor markets are the main reason to consider the reform. 
A random sample of 2,000 people aged 25-58 years who were receiving unemployment benefits at the end of 2016 was selected by the researchers. The participation of the selected individuals was compulsory. A UBI of $€ 560$ per month is being paid at the beginning of each month for 2 years. The UBI is exempt from tax and are not reduced even when the payee starts working full-time or part-time. (KELA, 2016)

The control group contains 173,000 people who have the same characteristics as the experimental group. They have access to the current social system. UBI is lower than the unemployment benefits. However, the unemployment benefits are reduced by $50 \%$ when their recipients start working part-time. The participants will not be contacted by any researchers, nor will any initial results be published to avoid influencing the behavior of the experimental group during the experiment. KELA aims only at detecting the difference between the employment of the test group and the control group.

Another UBI pilot project is under preparation in the Canadian province of Ontario. The impact of the UBI paid over three years to the lowincome population will be examined. Specifically, the impact on employment, health status, food security, housing stability and educational outcomes will be assessed. The project will take place in three cities selected to represent the population living in a typical urban area, rural area and a combination of the two. At the end of spring 2017, selected participants in the cities of Hamilton and Thunder Bay received information about project, and in autumn 2017 in Lindsay.

However, the UBI will not be a fixed payment in the Canadian field experiment. Every earned dollar will reduce the basic income by 50 cents. A single-person household receives up to C\$ 16,989 per year, two-person households up to $C \$ 24,027$ and an extra $C \$ 6,000$ in the case of disability. There will be a total of 4,000 randomly selected people aged 18-64 with a low income. The rest of the given population will serve as a control group. The participation will be voluntary and individuals in experimental group will be able to leave the project at any time. Some current social benefits, such as child benefits, tax relief, and benefits for medicine, will remain in effect and will be paid alongside UBI. The results of the project will be published in 2020 . (Government of Ontario, 2017) Other pilot projects are being prepared in the Netherlands, Scotland, California and/or San Francisco. UBI was also tested in the 2000s in Africa (Uganda, Kenya, Namibia) and India. Their results are not included in the paper due to the different economic and social conditions of these countries.

\section{Methodological limitations of the field experiments}

Although field experiments are the closest situation to the real implementation of unconditional basic income, it should be noted that their 
results are limited in several ways. In principle, all constraints stem from the design of the experiments, because the projects tested a system that is similar to UBI, but some of its characteristics were not met. The first problem is the choice of an experimental group, which contained primarily poor households or unemployed individuals. For the selection of participants, the universality and individual basis of UBI were not met. The recorded changes in labor supply are therefore not representative with respect to the general population.

The second problem is the size of UBI, or of the negative income tax amount, respectively. In most of the experiments, the amount was lower than the one proposed at the level of the relative poverty line and was also often cut, depending on the amount of labor income. Thus, an experiment setting did not meet the requirements of unconditionality and of a sufficient amount. The third problem is the limited duration of the projects. The impact on the participants' behavior was therefore certainly more limited than if they knew the UBI would be guaranteed throughout their life. The fourth difficulty is the possible presence of the Hawthorne Effect, which states that the behavior of the participants of an experiment may change not due to the experimental treatment, but because they know that they are being observed. The fifth problem is related to the drop-out rate of experiments, which reduced the data set and the number of results. In the Seattle-Denver experiment, $28 \%$ of households did not complete the experiment, in Winnipeg it was 36\%. (Hum \& Simpson, 1993)

The sixth problematic issue of pilot projects can be seen in their funding. All projects were subsidized from public sources, not from the tax revenues obtained from recipients of the tested unconditional benefit, as would be the case with a real nationwide implementation. Therefore, the financial sustainability of the system, which presents key issue in the possibility of introducing UBI, was not tested.

The last of the most fundamental issues concerns the way of collecting data during the experiment. The participants in the New Jersey project completed monthly questionnaires showing the amount of their labor income that determined their negative income taxes this month. Apart from these, they also completed quarterly more detailed questionnaires focusing on the number of hours worked, the composition of the consumption basket, political beliefs and marital coexistence (Carfinkel, 1972). In the Seattle-Denver pilot project, researchers visited the experimental families. The families did not have to fill in the questionnaires truthfully. The answers could have been chosen so that they could appear in a better light before the researchers or they could be influenced by the formulation or order of the questions. All the abovementioned issues need to be reflected in the discussion on what impact a real implementation of UBI could have on the labor supply. 


\section{Laboratory experiment with unconditional basic income}

Another way to obtain relevant data is using a laboratory experiment. Laboratory experimentation offers a highly controlled environment that provides better conditions for monitoring causal phenomena. Execution is less costly and less demanding administratively. Another advantage of a laboratory experiment is the possibility of its replication or an easier change of its design. ${ }^{2}$ According to Noguera and De Wispelaere (2006), Kahneman's and Tversky's behavioral experiments can be adapted for the research of UBI. Instead of bets, respondents can choose between UBI and other social security systems.

The first laboratory experiment with UBI was performed on 108 students of the university in Innsbruck (Haigner \& al., 2012). The participants were divided into anonymous groups of three members and at the beginning of each round they chose one of three options: (i) to work only for themselves; (ii) to work for a group; (iii) not to work and to enjoy leisure time instead. Subsequently, they dealt with mathematical tasks in eight rounds for five minutes, and they received an income of $€ 0.30$ for each problem correctly solved.

For those who opted for (i), the reward for the solved tasks was credited to an individual account, to those who opted for (ii) to a group account that was equally divided at the end of the experiment. Those who opted for (iii) did not solve tasks and could use the computer at will, such as for browsing websites or social networks. After each round, each participant knew only his or her performance. The first test group was taxed at 50\% and the tax revenue was then divided equally among the members of the group. At the beginning of the experiment, the second test group received $€ 15$ in an envelope and then earned the same income as the first group, but the tax revenue was given to the experimentalists. An amount of $€ 15$ was a standard reward for a participation in an experiment at Innsbruck University. The control group was taxed at $0 \%$. The first round of tasks was a trial period to determine the individual productivity of the participants. (Haigner \& al., 2012)

Two hypotheses were tested. The researchers assumed the most frequent choice (ii) and (iii) in the second test group and the least common in the control group. The highest productivity in solving tasks was expected in the control group, the weakest in the second test group. The first hypothesis was not confirmed. There was no significant difference between groups in choosing how they should be paid for work. The second hypothesis was also not supported by statistically significant results. The greatest number of correctly calculated tasks were reported by the control group, and the difference between the first and the second test group was only $6 \%$.

\footnotetext{
${ }^{2}$ Regarding to use laboratory experiments in macroeconomics, see Chytilova (2013).
} 
The tax revenue per participant was $€ 15.27$ in the first test group and only $€ 14.43$ in the second group, which was not enough to cover the UBI received before the experiment started ( $€ 15)$. The lowest income inequality was obtained by the second test group (Gini coefficient 0.118 ), the highest by control group (0.193). In the first test group, the inequality was slightly lower than in the control group (0.178) (Haigner \& al., 2012). The UBI thus reduced an income inequality with a minimal impact on the relative output of the group relative to the other two groups and with a modest budget deficit.

\section{Methodological limitations of the laboratory experiment}

The relevance of laboratory experiment is also limited in the context of UBI. The lab environment is far too simple and artificial. The first problem is the environmental validity of the lab experiment. To what extent would the participants' behavior in the real world be consistent with their choices in a lab? The Hawthorne Effect is perhaps even more relevant here than in more 'natural' settings. The selection of participants is also problematic voluntarily participating students of one Austrian university are hardly a representative sample of any relevant population. Therefore, the results cannot be easily generalized. The fourth problem is the duration of the experiment (75 minutes), which cannot detect changes in behavior due to long-term payment of UBI. The fifth problem lies in the strong simplification of the concept of work (solving of mathematical tasks) and leisure time (the participant had to stay in the room at his computer) in the experiment. The sixth limitation follows from the lack of replication of this experiment, which would verify how vulnerable the results are. All these shortcomings point to a significant limitation of the data obtained in this way regarding UBI.

\section{Estimates of microsimulation models}

Microsimulation models are used to estimate the financial requirements of a UBI system and a tax schedule that would keep it fiscally neutral. Microsimulations use a Statistics on Income and Living Conditions (SILC) dataset or data from tax returns and contain estimates of labor supply elasticity in some studies. The models generally predict a very low decrease in labor supply. Italian microsimulation results predict a minimum reduction in the number of hours worked after introduction of a combination of UBI and wage subsidies totaling $70 \%$ of the relative poverty line. From the original 1,968 hours per year for men, the model estimates a decrease by only five hours, for women a drop from 973 hours to 969. (Colombino \& Narazani, 2013)

Another estimate of the impact of UBI was carried out in Germany (Horstschräer, Clauss \& Schnabel, 2010). It tested a proposal by the German political party Christlich Demokratische Union Deutschlands (CDU) that 
counted on the abolition of all social benefits and their replacement by citizens' income in the form of a negative income tax of $€ 600 /$ month for all adults and $€ 300 /$ month for children, accompanied by a change in the tax system, including changes in health insurance. However, the analysis showed a significant financial deficit of the proposed system, although the impact on the labor supply was estimated to be positive. The German microsimulation on 12,000 households of over 23,000 individuals in 2004 estimated an increase in the number of hours worked by $2.2 \%$ for men and by $3.72 \%$ for women. (Horstschräer, Clauss \& Schnabel, 2010)

A microsimulation of a more realistic fiscally neutral system with the same negative tax rate as the German CDU's proposal, adjusted for a higher income tax rate of $61.3 \%$ on individuals, showed a negative impact on labor supply. For men, the hours worked were estimated to fall by $0.59 \%$ and $0.71 \%$ for women. A greater drop of $1.35 \%$ was estimated for women living in a shared household with a man. Overall, the number of active people in the labor market dropped by $0.51 \%$, due to the dropout of women. It was estimated that the increase in number of men in the labor market was $0.74 \%$ and the decrease in the number of women by $1.85 \%$. (Horstschräer, Clauss \& Schnabel, 2010)

\section{Methodological limitations of microsimulation models}

Microsimulations are generally used to determine the impact of tax or social reforms on individuals and households. The estimates of these models depend on the quality of the input data, but also on the model itself. Their use in predicting the labor supply in the UBI system is therefore limited for the following reasons. The labor supply is a complex problem. Many behavioral factors (not only economic at first sight) enter in regarding the decision to participate or not in the labor market and the extent of participation that cannot be included in the simulation. Therefore, the models are not able to perfectly simulate new conditions with new motivations in which labor supply choices would be made. Given that UBI and heavy income taxation would be a major change for households, the model estimates can perhaps tell us the direction in which labor supply would change, but not the scope of a change. For further advantages and disadvantages of applying microsimulation modeling in tax and social policy, see Stepankova (2002). The changes of the behavior of individuals or households can be better observed in field or laboratory experiments.

\section{Opinion survey records}

The last of the possibly relevant data sources are polls. In March and April 2016, an opinion survey on UBI has been conducted in 28 countries of the European Union, attended by 10,000 respondents aged 14-65 from 500 different cities (Jaspers, 2016). The biggest concerns expressed regarding UBI 
were that people would stop working (43\% of respondents) and that immigration would increase $(34 \%)$. The worry that the system would be impossible to fund was ranked third (32\%). However, only $4 \%$ of respondents said they would stop working with a basic income. $34 \%$ would not change their working habits at all, $15 \%$ would spend more time with their family and $10 \%$ would invest more in their human capital. Asked how they would vote in the case of a referendum on the introduction of basic income, the largest support of UBI has been found in Spain (71\%) and Italy (69\%). (Jaspers, 2016)

A similar survey was carried out in Switzerland in 2015. $2 \%$ of respondents said they would certainly cease to work with a UBI, and another $8 \%$ said they probably would. $69 \%$ of the respondents claimed they would not stop working. The gender difference was only one percentage point. $78 \%$ from a cohort of young people aged 18-34 would certainly not stop working with a UBI. (DemoSCOPE, 2015)

\section{Methodological limitations of opinion surveys}

The informative value of public opinion surveys is also considerably limited. Respondents can be influenced by cognitive factors such as the ordering of questions, use of certain words, the framing of the question or the proposed answers. The data obtained in this way may also be distorted by the social desirability bias. In addition, human attitudes may be unstable over time (Mullainathan \& Bertrand, 2001). For opinion surveys is also typical a large component of randomness in most people's answers to survey question (Zaller \& Feldman, 1992).

Opinion surveys on UBI topic are only able to find out stated preferences, not revealed, because the introduction of UBI is only a hypothetical decision context for respondents. It is difficult for respondents to estimate the change in labor supply in hypothetical conditions they have never experienced before. Their real behavior could be quite different from what they expect.

\section{Prediction of labor supply changes caused by UBI: A Summary}

Based on the available data, what can we say about the changes in labor supply that would occur if an UBI were introduced? Most data point towards a drop in the labor supply. The research on lottery winners shows that $6-23 \%$ of financially secured individuals leave the labor market, and another $7-14 \%$ decrease their labor supply. However, it should be added to these figures that the winnings were much higher than UBI would be.

The decline in labor supply was also measured in pilot projects in the US and Canada. The income elasticity of labor supply in the oldest of the field experiments was estimated at -0.02 (Hausman \& Wise, 1976). After the first year of research, the hours worked decreased by $11.8 \%$ per household, while 
the impact on men was smaller than the impact on women (Carfinkel, 1972). The gender difference was also confirmed in other experiments. In addition, the Seattle-Denver experiment has shown that plans with high negative income taxes and high marginal tax rates have reduced labor supply more severely than plans that offered a lower negative tax and lower marginal tax rate. Overall, in all four American experiments, an average drop in hours worked was $7 \%$ for men and $17 \%$ for women (Munnell, 1987). The Canadian experiment did not bring any statistically significant results.

The results of the laboratory experiment did not show a decrease in work effort for those participants who were paid before the start of the experiment regardless of their performance. It has not been shown that they have more often chosen to use the computer for leisure activities instead of solving mathematical tasks, even though this option had been offered to them. (Haigner \& al., 2012) However, the value of this data source is rather small due to particularly severe methodological limitations.

The microsimulations predict a lower decline in labor supply than pilot projects or lottery winners research. The model estimated on Italian data predicts a small drop in the supply of labor for both women and men (Colombino \& Narazani, 2013). The German microsimulation of a fiscally neutral system of unconditional income predict a fall in hours worked by men by about $0.6 \%$, by women by $0.7 \%$. The overall decline in labor-market participation by $0.5 \%$ would be caused by a reduction in the number of working women by $1.85 \%$. (Horstschräer, Clauss \& Schnabel, 2010) In opinion surveys, only a small proportion of respondents claimed that they would stop working if they were receiving UBI. In the European survey it was only 4\%, in the Swiss 2-10\% (Jaspers, 2016; DemoSCOPE, 2015).

\section{Conclusion}

All five data sources examined have some relevance towards the prediction of elasticity of labor supply with respect to UBI. It is nevertheless necessary to take into account their limitations. None of them can provide us with an accurate prediction of the change in human behavior caused by UBI. It is equally important to add that the article does not deal with the forecasts for the entire labor market but looks only at its supply side. Another simplification of the problem was that only a change in the behavior of people who would move from the current social welfare system to a system of unconditional income was examined. Individuals who were already born into the new system could, of course, not be examined.

Most available sources predict a decline in labor supply. The strongest impact is found among the lottery winners; the microsimulation models predict a very weak decline; the laboratory experiment finds an insignificant change. The most relevant results come from the field experiments from the 
US and Canada in which there was a slight decline in labor supply (a few percentage points), and also a greater change in women's labor supply than in men's. The data from the ongoing experiment in Finland and the forthcoming project in Canadian Ontario will bring new results to help answer the question of whether and how much people would work if they could rely on certain and sufficiently high non-labor income.

\section{References:}

1. Anderson, E. (2000). Optional Freedoms. Boston Review. Retrieved from: http://bostonreview.net/forum/basic-income-all/elizabethanderson-optional-freedoms

2. Arcarons, J., Raventos, D., \& Torrens, L. (2014). Feasibility of Financing a Basic Income. Basic Income Studies, 9(1-2), 79-93.

3. Arvey, R., Harpaz, I., \& Liao, H. (2004). Work Centrality and PostAward Work Behavior of Lottery Winners. The Journal of Psychology, 138(5), 404-420.

4. BIEN. Basic Income Earth Network. (2017). What Is Basic Income? Retrieved from: http://basicincome.org/basic-income/

5. Carfinkel, I. (1972). The New Jersey Income Maintenance Experiment. The Journal of Consumer Affairs (Pre-1986), 6(1).

6. Chytilova, H. (2013). Methodological Considerations of Macroeconomic Experiments. In Prague Macroeconomics \& Finance Conference Proceedings. Praha: International Institute of Social and Economic Sciences (IISES), 237-47.

7. Colombino, U., \& Narazani, E. (2013). Designing a Universal Income Support Mechanism for Italy: An Exploratory Tour. Basic Income Studies, 8(1), 1-17.

8. DemoSCOPE. (2015). OMNIBUS SUISSE 2015: Repräsentativbefragung Bedingungsloses Grundeinkommen. Retrieved from: http://www.basicincome.org/wpcontent/uploads/2016/01/grundeinkommen-opinion-poll_2015.pdf

9. Elster, J. (1986). Comment on van Der Veen and Van Parijs. Theory and Society, 15(5), 709-21.

10. Ford, M. (2016). Rise of the Robots: Technology and the Threat of a Jobless Future. Reprint edition. New York: Basic Books.

11. Forget, E. (2011). The Town with No Poverty: The Health Effects of a Canadian Guaranteed Annual Income Field Experiment. Canadian Public Policy, 37(3), 283-305.

12. Friedman, M. (1962). Capitalism and Freedom: Fortieth Anniversary Edition. University of Chicago Press. 
13. Galston, W. (2000). What About Reciprocity? Boston Review. Retrieved from: http://bostonreview.net/forum/basic-incomeall/william-galston-what-about-reciprocity

14. Government of Ontario. (2017). Ontario Basic Income Pilot. Retrieved from: https://www.ontario.ca/page/ontario-basic-income-pilot

15. Groot, L. (2004). Basic Income, Unemployment and Compensatory Justice. Springer US.

16. Haigner, S. \& al. (2012). Keep on Working: Unconditional Basic Income in the Lab. Basic Income Studies, 7(1).

17. Hausman, J., \& Wise, D. (1976). The Evaluation of Results from Truncated Samples: The New Jersey Income Maintenance Experiment. In NBER Chapters, 421-45. National Bureau of Economic Research. Retrieved from: https://ideas.repec.org/h/nbr/nberch/10489.html

18. Healy, S. \& al. (2012). Basic Income-Why and How in Difficult Economic Times: Financing a BI in Ireland. In 14th International Congress of the Basic Income Earth Network, Munich, Germany (pp. 14-16).

19. Hedenus, A. (2012). Who Wants to Work Less? Significance of SocioEconomic Status and Work Conditions for Work Commitment among Swedish Lottery Winners. Acta Sociologica, 55(4), 335-50.

20. Horstschräer, J., Clauss, M., \& Schnabel, R. (2010). An Unconditional Basic Income in the Family Context - Labor Supply and Distributional Effects. ZEW - Centre for European Economic Research Discussion Paper, No. 10-091.

21. Hum, D., \& Simpson, W. (1993). Economic Response to a Guaranteed Annual Income: Experience from Canada and the United States. Journal of Labor Economics, 11(1), 263-96.

22. Imbens, G., Rubin, D., \& Sacerdote, B. (2001). Estimating the Effect of Unearned Income on Labor Earnings, Savings, and Consumption: Evidence from a Survey of Lottery Players. American Economic Review, 91(4), 778-794.

23. Jaspers, N. (2016). What Do Europeans Think about Basic Income? Retrieved from: http://www.basicincome.org/wpcontent/uploads/2016/05/EU_Basic-Income-Poll_Results.pdf

24. Kaplan, R. (1987). Lottery Winners: The Myth and Reality. Journal of Gambling Behavior, 3(3), 168-78.

25. KELA. (2016). Basic Income Experiment 2017-2018. Retrieved from: http://www.kela.fi/web/en/basic-income-experiment-2017-2018

26. Levine, R. \& al. (2005). A Retrospective on the Negative Income Tax Experiments: Looking Back at the Most Innovative Field Studies in Social Policy, in Widerquist, K., Lewis, M., Pressman, S., ed., The 
ethics and economics of the basic income guarantee. Aldershot, UK: Ashgate, pp. 95-106.

27. Marx, A., \& Peeters, H. (2004). Win for Life. What, If Anything, Happens after the Introduction of a Basic Income? Conference lecture. Basic Income European Network, 10th International Congress, Barcelona. Retrieved from: http://www.basicincome.org/bien/pdf/2004MarxPeeters.doc

28. Mullainathan, S., \& Bertrand, M. (2001). Do People Mean What They Say? Implications for Subjective Survey Data. American Economic Review, 91(2), 67-72.

29. Munnell, A. (1987). Lessons from the Income Maintenance Experiments: An Overview. New England Economic Review, May, 3245.

30. Noguera, J., \& De Wispelaere, J. (2006). A Plea for the Use of Laboratory Experiments in Basic Income Research. Basic Income Studies, 1(2).

31. Office of the Assistant Secretary for Planning and Evaluation. (1983). Overview of the Final Report of the Seattle-Denver Income Maintenance Experiment. Retrieved from: https://aspe.hhs.gov/report/overview-final-report-seattle-denverincome-maintenance-experiment

32. Raventos, D. (2007). Basic Income: The Material Conditions of Freedom. Pluto Press.

33. Schneider, O. (2016). Zakladni prijem je cesta do pekla $\left(2016,15^{\text {th }}\right.$ January). Hospodarske noviny. Retrieved from: https://archiv.ihned.cz/c1-65094190-zakladni-prijem-je-cesta-dopekla

34. Stepankova, P. (2002). Vyuziti mikrosimulacniho modelovani v hodnoceni redistribucni funkce dani a socialnich davek. Finance a uver, 52(2), 36-50.

35. Tobin, J. (1966). The Case for an Income Guarantee. The Public Interest, 4, 31-41.

36. Van Parijs, P., \& Vanderborght, Y. (2012) Basic Income in a Globalized Economy. In Reynolds, B., \& Healy, S. (eds.). Does the European Social Model Have a Future?. Dublin: Social Justice Ireland, pp. 31-60.

37. Van Parijs, P. (2000). A Basic Income for All. Boston Review, 25(5), 4-8.

38. Zaller, J., \& Feldman, S. (1992). A Simple Theory of the Survey Response: Answering Questions versus Revealing Preferences. American Journal of Political Science, 36(3), 579-616. 